\title{
Determinación del porcentaje de viabilidad espermática mediante citometría de flujo durante el proceso de criopreservación en espermatozoides obtenidos de epidídimo de alpaca
}

\author{
Sperm viability percentage by flow cytometry during the cryopreservation \\ process in spermatozoa obtained from alpaca epididymis
}

\author{
Javier Juárez ${ }^{1}$, Alexei Santiani ${ }^{1,2}$
}

\section{Resumen}

El objetivo del estudio fue determinar el porcentaje de viabilidad en espermatozoides epididimarios de alpaca, antes y después del proceso de criopreservación, mediante citometría de flujo. Se recolectaron 46 testículos de alpaca de un camal de Pasco, Perú y se utilizaron 41 de ellos con motilidad espermática $\geq 30 \%$ y concentración espermática $\geq 50 \times 10^{6}$ espermatozoides $/ \mathrm{ml}$. Los espermatozoides fueron recuperados de la cola del epidídimo con $1 \mathrm{ml}$ de dilutor a base de leche descremada. separándose en dos alícuotas para evaluar la viabilidad antes y después del proceso de criopreservación. El dilutor fue retirado mediante lavados por centrifugación con PBS, los pellets fueron resuspendidos en $100 \mu \mathrm{l}$ de PBS, agregándose $0.5 \mu \mathrm{l}$ de SYBR-14 (100 nM) y $0.5 \mu 1$ de ioduro de propidio - PI $(12 \mu \mathrm{M})$ incubándose por $10 \mathrm{~min}$ a $38^{\circ} \mathrm{C}$. La evaluación de viabilidad espermática se realizó mediante citometría de flujo con analizador de imágenes, utilizando un láser de excitación de $488 \mathrm{~nm}$ y la fluorescencia emitida por el SYBR-14 y el PI fueron detectados por los canales Ch02 (505-560 nm) y Ch05 (642-740 nm), respectivamente. Los espermatozoides viables con membrana intacta emitieron fluorescencia verde (SYBR-14) y los espermatozoides no viables con membrana dañada emitieron fluorescencia roja (PI). La viabilidad antes del proceso de criopreservación $(48.97 \pm 11.47 \%)$ fue mayor $(\mathrm{p}<0.05)$ que después del proceso de criopreservación $(32.30 \pm 9.57 \%)$. La correlación entre viabilidad y motilidad espermática fue $\mathrm{r}=0.6737$. Se concluye que el proceso de criopreservación disminuye significativamente la viabilidad en espermatozoides epididimarios de alpaca, estando este parámetro relacionado con la motilidad.

Palabras clave: alpaca; espermatozoide; viabilidad; SYBR-14; ioduro de propidio; motilidad

\footnotetext{
${ }^{1}$ Laboratorio de Reproducción Animal, Facultad de Medicina Veterinaria, Universidad Nacional Mayor de San Marcos, Lima, Perú

${ }^{2}$ E-mail: asantiania@unmsm.edu.pe
}

Recibido: 16 de diciembre de 2018

Aceptado para publicación: 18 de julio de 2019 
The aim of this study was to determine the percentage of viability in alpaca epididymal spermatozoa before and after the cryopreservation process by flow cytometry. A total of 46 alpaca testes were collected from a slaughterhouse in Pasco, Peru and 41 of them were used with sperm motility $\geq 30 \%$ and sperm concentration $\geq 50 \times 10^{6} \mathrm{sperm} / \mathrm{ml}$. Spermatozoa were recovered from the tail of the epididymis with $1 \mathrm{ml}$ of skimmed milk-based extender, separating into two aliquots to evaluate viability before and after the cryopreservation process. The extender was removed by washing by centrifugation with PBS, the pellets were resuspended in $100 \mu \mathrm{l}$ of PBS, adding $0.5 \mu \mathrm{l}$ of SYBR-14 $(100 \mathrm{nM})$ and $0.5 \mu \mathrm{l}$ of propidium iodide - PI $(12 \mu \mathrm{M})$, and incubated for $10 \mathrm{~min}$ at $38^{\circ} \mathrm{C}$. The evaluation of sperm viability was performed by flow cytometry with image analyzer, using an excitation laser of $488 \mathrm{~nm}$ and the fluorescence emitted by SYBR-14 and PI were detected by channels Ch02 (505-560 nm) and Ch05 (642-740 nm), respectively. Viable spermatozoa with intact membrane emitted green fluorescence (SYBR-14) and non-viable sperm with damaged membrane emitted red fluorescence (PI). The viability before the cryopreservation process $(48.97 \pm 11.47 \%)$ was higher $(\mathrm{p}<0.05)$ than after the cryopreservation process $(32.30 \pm$ $9.57 \%$ ). The correlation between viability and sperm motility was $r=0.6737$. It is concluded that the cryopreservation process significantly reduces the viability in alpaca epididymal spermatozoa, and viability is related to sperm motility.

Key words: alpaca; sperm; viability, SYBR-14; propidium iodide; motility

\section{INTRODUCCIÓN}

La criopreservación de semen ofrece la posibilidad de almacenamiento por un largo periodo; sin embargo, la alta viscosidad del plasma seminal y la mala calidad de los eyaculados son las principales desventajas para el desarrollo de una técnica de congelación (Malo et al., 2018). Durante años, la evaluación de la viabilidad de espermatozoides se ha basado en procedimientos microscópicos que utilizan métodos de tinción simples o duales; siendo los más populares la tinción eosina-nigrosina (EN) y la doble tinción. En estos, la confiabilidad de la prueba para la evaluación de la viabilidad espermática es cuestionable ya que se basan en una población relativamente pequeña (hasta 200 células por muestra) y la precisión durante la evaluación es subjetiva porque depende del observador (Klimowicz-Bodys et al., 2012).
En las últimas décadas se están utilizando los fluorocromos SYBR-14 e ioduro de propidio (PI) para determinar la viabilidad espermática en diferentes especies. El SYBR-14 es permeable a la membrana y tiñe el ADN de los espermatozoides vivos y el PI solo puede atravesar la membrana de espermatozoides muertos y teñir su ADN (Cabrita et al., 2005; Paniagua-Chávez et al., 2006). Estos fluorocromos se han utilizado para evaluar semen fresco y descongelado de mamíferos y aves, donde la microscopía de fluorescencia es la principal técnica utilizada para la evaluación de viabilidad espermática; sin embargo, este procedimiento es muy laborioso y demandante de tiempo. Por otro lado, la evaluación de la viabilidad espermática por citometría de flujo proporciona un método rápido, objetivo y preciso al momento de evaluar el porcentaje de espermatozoides vivos (Klimowicz-Bodys $e t$ al., 2012). 
Se han estudiado diversas técnicas de tinción para la evaluación de parámetros espermáticos en alpacas; así, Santiani et al. (2005) evaluaron viabilidad espermática mediante doble tinción en muestra fresca y después de la congelación, Cheuquemán et al. (2013) evaluaron viabilidad espermática en muestras frescas utilizando los fluorocromos SYBR-14 y PI, en tanto que Banda et al. (2010) y Santiani et al. (2013) evaluaron un parámetro mixto que incluye vitalidad e integridad acrosomal. De estos estudios, solo el de Santiani et al. (2005) evaluó viabilidad espermática antes y después de la congelación en alpacas utilizando una técnica antigua de Didion et al. (1989).

Dado la importancia del proceso de criopreservación para la conservación de semen y que la citometría de flujo permite la evaluación de la viabilidad espermática; y al no existir estudios contundentes sobre como la criopreservación afecta la viabilidad espermática es que el presente estudio tuvo por objetivo determinar el porcentaje de viabilidad en espermatozoides obtenidos de epidídimo de alpaca mediante citometría de flujo, antes y después del proceso de criopreservación.

\section{Materiales y Métodos}

\section{Lugar de Estudio y Muestras}

El estudio se realizó en el Laboratorio de Reproducción Animal de la Facultad de Medicina Veterinaria de la Universidad Nacional Mayor de San Marcos (Lima, Perú). Se recolectaron 46 testículos del Camal Municipal del distrito de Ninacaca, provincia de Pasco, Perú, entre mayo y junio de 2016. Luego del beneficio, los testículos fueron lavados con solución fisiológica $(\mathrm{NaCl} 0.9 \%)$ y colocados en bolsas herméticas individuales junto con solución fisiológica ( $\mathrm{NaCl} 0.9 \%)$, almacenados en cajas transportadoras a una temperatura de $5{ }^{\circ} \mathrm{C}$, y trasladados al labora- torio. Solo se trabajaron aquellos testículos que cumplían con los requerimientos mínimos: peso $\geq 10 \mathrm{~g}$, longitud $\geq 3 \mathrm{~cm}$ (Abraham et al., 2016).

\section{Procedimiento Metodológico}

Se retiró la túnica vaginal visceral y túnica albugínea de cada testículo y se separó la cola del epidídimo. Se lavó la cola del epidídimo con buffer fosfato salino (PBS) y se colocó en una placa Petri temperada a $37{ }^{\circ} \mathrm{C}$, agregándose $1 \mathrm{ml}$ de dilutor $(19 \mathrm{ml}$ leche descremada, $1 \mathrm{ml}$ yema de huevo, 0.97 $\mathrm{g}$ fructosa). Además, se añadió $1840 \mu \mathrm{l}$ de crioprotector dimetilacetamida para llegar a una concentración final de $1 \mathrm{M}$, y se les mantuvo a $37^{\circ} \mathrm{C}$. Se realizaron cortes seriados en la cola del epidídimo con la ayuda de una pinza y una hoja de bisturí para permitir la liberación de los espermatozoides.

Se recuperó $1 \mathrm{ml}$ por muestra, manteniéndose temperado a $37^{\circ} \mathrm{C}$. Se evaluó la motilidad (\%) y concentración espermática (espermatozoides $/ \mathrm{ml}$ ). Se seleccionaron solo 41 muestras que tenían una motilidad $\geq 30 \%$ y una concentración $\geq 50 \times 10^{6}$ espermatozoides $/ \mathrm{ml}$. Cada muestra fue dividida en 2 alícuotas para evaluar el porcentaje de viabilidad espermática antes y después del proceso de criopreservación.

Para realizar el proceso de criopreservación de las pajillas se utilizó el programa 7 del sistema automático de congelamiento Freeeze Control ${ }^{\circledR}$ (Cryologic, Australia), el cual utiliza nitrógeno líquido. El proceso se inicia a $18^{\circ} \mathrm{C}$ disminuyendo hasta $5^{\circ} \mathrm{C}$ en un lapso de 90 minutos, para luego mantenerse así por 30 minutos y después de transcurrido este tiempo se sigue disminuyendo la temperatura hasta la congelación. Las pajillas fueron retiradas luego del proceso de congelamiento y colocadas en un tanque de nitrógeno líquido. Para el descongelamiento, las pajillas fueron sumergidas en baño maría a $37^{\circ} \mathrm{C}$ por un minuto. 


\section{Viabilidad Espermática}

La viabilidad espermática fue evaluada antes y después del proceso de criopreservación. Cada muestra se lavó dos veces por centrifugación con PBS a 600 x g por 8 minutos, eliminándose el sobrenadante y el pellet se resuspendió en $100 \mu 1$ de PBS.

Se empleó el LIVE/DEAD ${ }^{\circledR}$ Sperm Viability Kit (L-7011, Molecular Probes), el cual contiene el fluorocromo SYBR-14 que emite fluorescencia verde como indicador de espermatozoides viables con membrana plasmática intacta y el fluorocromo ioduro de propidio (PI) que emite fluorescencia roja como indicador de espermatozoides no viables con membrana plasmática dañada. Se tomaron $100 \mu \mathrm{l}$ de muestra después del lavado y se agregó $0.5 \mu \mathrm{l}$ de solución stock de SYBR-14 $(20 \mu \mathrm{M})$ para obtener una concentración final de $100 \mathrm{nM}$. Se agregó además $0.5 \mu 1$ de solución stock de PI (2.4 mM) para llegar a una concentración final de PI de $12 \mu \mathrm{M}$ y se puso a incubar a $38^{\circ} \mathrm{C}$ por 10 minutos.

\section{Citometría de Flujo}

Las evaluaciones se realizaron mediante un citómetro de flujo FlowSight (Amnis, USA) que tiene un sistema analizador de imágenes. Se leyeron 10000 eventos compatibles con espermatozoides por cada muestra. Para la excitación del SYBR-14 y del PI se utilizó un láser de longitud de onda de $488 \mathrm{~nm}$ a una potencia de $15 \mathrm{~mW}$. La emisión de la fluorescencia para el SYBR-14 fue leída utilizando el canal de detección de 505 a 560 $\mathrm{nm}(\mathrm{Ch} 02)$ y la emisión de la fluorescencia para el PI fue leída utilizando el canal de detección de 642 a $740 \mathrm{~nm}$ (Ch05). Dado que el citómetro de flujo posee un sistema analizador de imágenes, se observaron fotos de espermatozoides vivos marcados con SYBR14 y muertos marcados con PI.
Cuadro 1. Evaluación de la viabilidad de espermatozoides (\%) obtenidos de epidídimos de alpacas, antes y después del proceso de criopreservación, utilizando los fluorocromos SYBR-14 e ioduro de propidio

\begin{tabular}{lcc}
\hline & Antes & Después \\
\hline Promedio & 48.97 & 32.30 \\
Mediana & 50.30 & 32.90 \\
Desviación estándar & 11.47 & 9.57 \\
Coef. de variación & 23.42 & 29.62 \\
Intervalo de & 3.62 & 3.02 \\
confianza & & \\
Distribución normal & Sí & Sí \\
\hline
\end{tabular}

Cuadro 2. Viabilidad espermática y motilidad antes y después del proceso de congelación de espermatozoides obtenidos de epidídimo de alpaca

\begin{tabular}{lcc}
\hline & Antes & Después \\
\hline Viabilidad & $48.97 \pm 11.47^{\mathrm{a}}$ & $32.30 \pm 9.57^{\mathrm{b}}$ \\
espermática & & \\
Motilidad & $46.10 \pm 7.71^{\mathrm{a}}$ & $24.07 \pm 6.50^{\mathrm{b}}$ \\
\hline
\end{tabular}

Promedios \pm desviación estándar

$a, b$ Letras diferentes dentro de filas indican

diferencia significativa $(p<0.05)$

\section{Análisis Estadístico}

Los porcentajes de viabilidad de espermatozoides antes y después del proceso de criopreservación fueron analizados mediante la prueba de t-Student de muestras pareadas. Para determinar si los datos obtenidos siguen la distribución normal se utilizó la prueba Kolmogorov-Smirnov. Para deter- 
Cuadro 3. Correlación de Pearson entre la viabilidad y la motilidad, presentada en muestras de espermatozoides obtenidos de epidídimo de alpaca antes y después del proceso de criopreservación.

\begin{tabular}{cccc}
\hline \multirow{2}{*}{$\begin{array}{c}\text { Parámetros } \\
\text { espermáticos }\end{array}$} & \multicolumn{2}{c}{$\begin{array}{c}\text { Correlación de } \\
\text { Pearson }\end{array}$} & \multirow{2}{*}{$\begin{array}{c}\text { Pares } \\
\text { (n) }\end{array}$} \\
\cline { 2 - 3 } & $\mathrm{r}$ & $\mathrm{p}$ & \\
\hline $\begin{array}{c}\text { Viabilidad } \\
\text { vs. } \\
\text { Motilidad }\end{array}$ & 0.6737 & $\mathrm{p}<0.0001$ & 82 \\
\hline
\end{tabular}

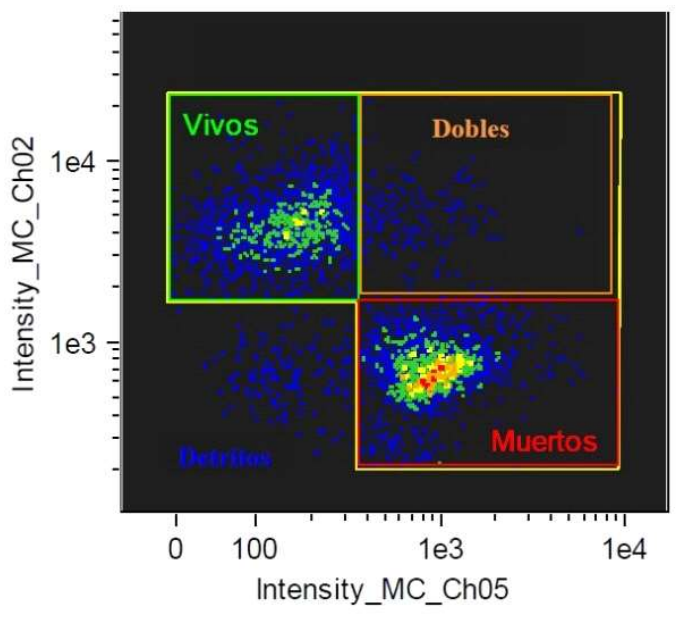

Figura 1. Gráfico Dot Plot representativo de espermatozoides después del proceso de criopreservación utilizando los fluorocromos SYBR-14 y Ioduro de Propidio (PI) donde aparecen cuatro poblaciones claramente diferenciadas. Cuadrante superior izquierdo: espermatozoides vivos; Cuadrante inferior derecho: espermatozoides muertos; Cuadrante superior derecho: espermatozoides vivos y muertos; Cuadrante inferior izquierdo: detritos. En el eje Y se observa la intensidad del canal Ch02 (SYBR-14) y en el eje X la intensidad del canal Ch05 (PI)

minar la correlación entre los porcentajes de viabilidad y motilidad se utilizó la prueba de coeficiente de correlación de Pearson. Todos los análisis fueron hechos con el programa GraphPad Prism ${ }^{\circledR}$ v. 3.0.

\section{Resultados}

En el Cuadro 1 se presentan los datos estadísticos obtenidos evaluando la viabilidad espermática y en la Figura 1 se presenta un gráfico Dot Plot representativo de espermatozoides después del proceso de criopreservación.

Los valores porcentuales de viabilidad y motilidad de los espermatozoides antes y después del proceso de criopreservación fueron estadísticamente diferentes ( $\mathrm{p}<0.05$, Cuadro 2). El análisis de correlación de Pearson entre los valores de viabilidad y motilidad mostró una correlación moderada positiva significativa (Cuadro 3). En la Figura 2 se presentan fotografías representativas de cada población con SYBR-14 y PI.

En la Figura 3 se observa la correlación entre el porcentaje de viabilidad y motilidad espermática presente en las muestras antes y después del proceso de criopreservación.

\section{Discusión}

Este es el primer estudio que presenta como los porcentajes de viabilidad en espermatozoides obtenidos de epidídimo de alpaca disminuyen significativamente luego del proceso de criopreservación. La viabilidad espermática inicial estuvo alrededor del $48 \%$, resultado menor al $57 \%$ reportado por Cheuquemán et al. (2013), posiblemente debido que las muestras de semen de dicho estudio provenían de un núcleo de reproductores en tanto que las del presente estudio provenían de animales de camal. Por otro lado, este grupo de autores obtuvo en un estudio previo una viabilidad espermática inicial de $45 \%$ (Santiani et al., 2013), similar al del presente estudio, posiblemente debido a que en ambos estudios se utilizaron muestras de animales de descarte. 


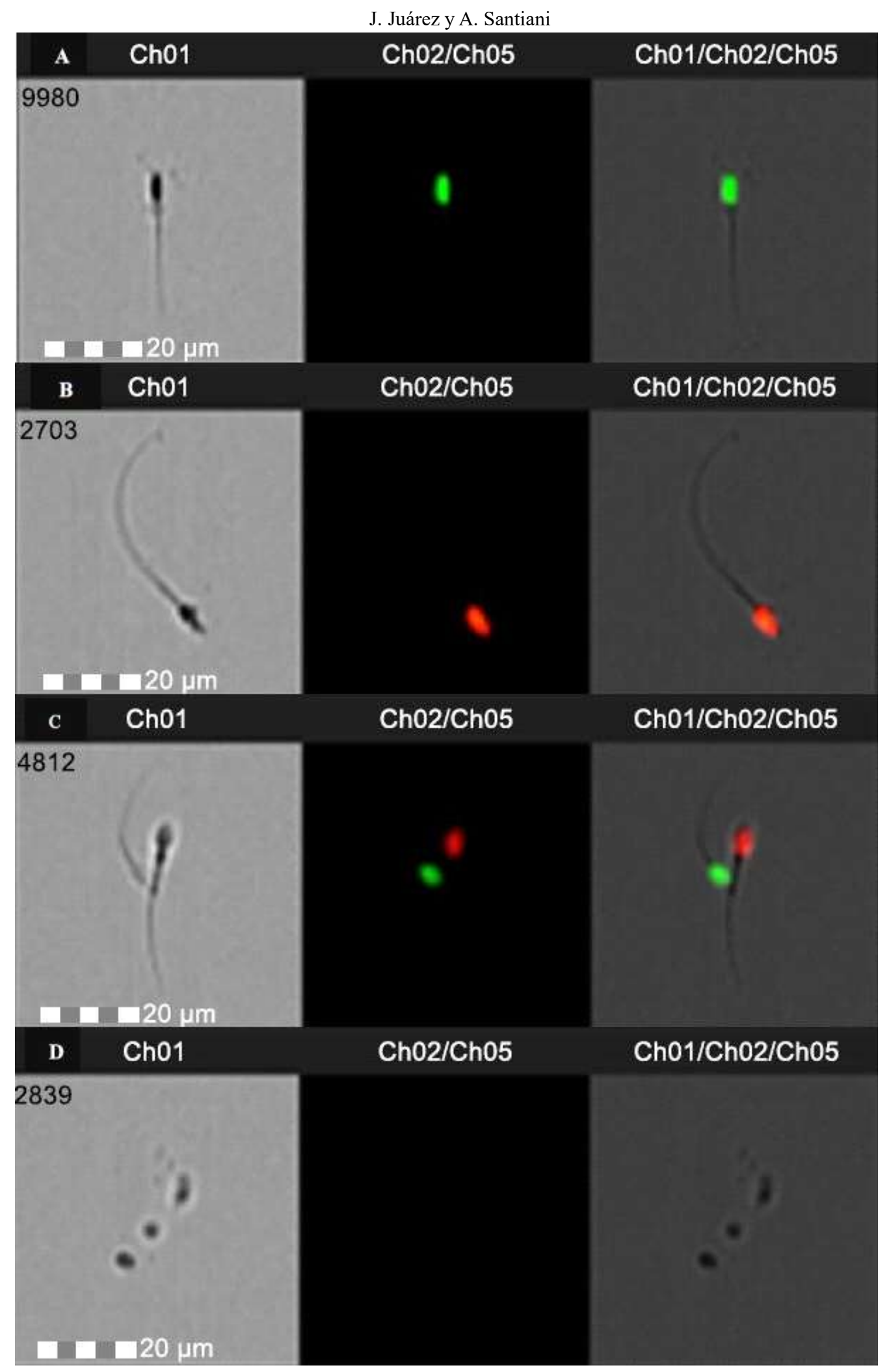

Figura 2. Espermatozoides epididimarios de alpaca analizados mediante citometría de flujo utilizando los fluorocromos SYBR-14 e ioduro de propidio (PI) observados en campo claro (Ch01), con fluorescencia (Ch02/Ch05), combinación de campo claro y fluorescencia (Ch01/Ch02/Ch05). (A) espermatozoide vivo emitiendo fluorescencia verde por el SYBR-14. (B) espermatozoide muerto emitiendo fluorescencia roja por el PI. (C) espermatozoide vivo y muerto emitiendo fluorescencia verde y roja respectivamente. (D) detritos, los cuales no emiten fluorescencia 


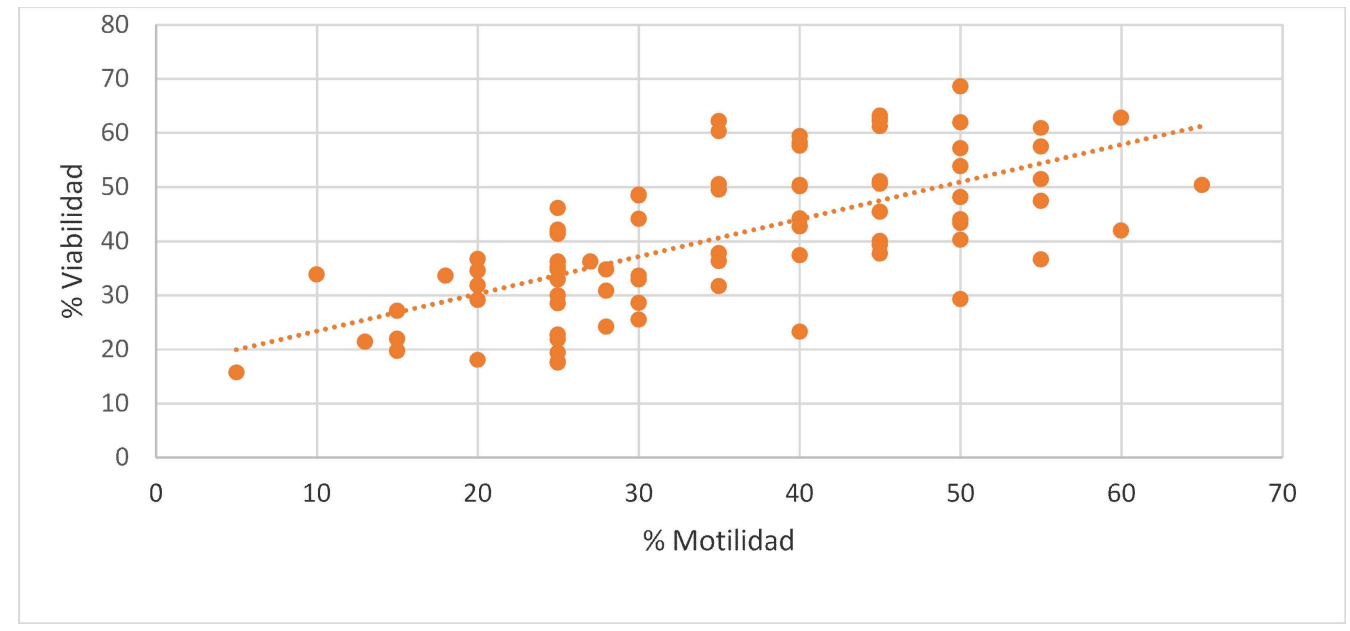

Figura 3. Correlación entre el porcentaje de viabilidad espermática y motilidad en espermatozoides obtenidos de epidídimo de alpaca

En las muestras descongeladas se observó una disminución de la viabilidad espermática que llegó hasta $32 \%$, valor superior a los reportados por Santiani et al. $(2005 ; 2013)$ y Banda et al. (2010) de 21, 2832 y $27 \%$ de espermatozoides viables posdescongelación. La mayor pérdida de espermatozoides viables en esos estudios podría deberse al dilutor empleado donde se empleó etilenglicol y en presente estudio se utilizó dimetilacetamida (DMA). Sin embargo, Santiani et al. (2013) reportaron valores entre 28 y $32 \%$ de viabilidad espermática posdescongelación, posiblemente debido a la adición de un análogo de superóxido dismutasa en las muestras, lo cual implicaría que algunos de los factores involucrados en mantener la viabilidad espermática en alpacas serían los crioprotectores y los antioxidantes.

La motilidad inicial de $46 \%$ descendió hasta $24 \%$ luego del proceso de congelación. Se reconoce que la motilidad es el parámetro más afectado durante el proceso de congelamiento (Canorio et al., 2015), además que se encuentra estrechamente relacionada con la viabilidad espermática (Henkel et al., 2005). Es por eso que una disminución en la motilidad espermática a menudo se interpreta como un indicador de la disminución en la viabilidad (Brown y Senger, 1980). En este sentido, la correlación de Pearson dio como resultado un valor de $r=0.6737$, indicativo de una correlación moderada positiva significativa.

Es interesante destacar que en este estudio se encontró mayor porcentaje de espermatozoides vivos que motiles. Esto es posible porque existen espermatozoides viables que no poseen motilidad, lo cual explica que aunque los espermatozoides no viables no tienen motilidad no se puede concluir que los espermatozoides viables tendrán necesariamente motilidad (Vetter et al., 1998).

\section{Conclusiones}

- La viabilidad de los espermatozoides obtenidos del epidídimo de alpaca disminuye significativamente luego del proceso de criopreservación.

- Existe una correlación moderada positiva entre la viabilidad y motilidad espermática de espermatozoides de alpaca. 


\section{Literatura Citada}

1. Abraham MC, Puhakka J, Ruete A, Al-Essawe EM, de Verdier K, Morrell JM, Båge R. 2016. Testicular length as an indicator of the onset of sperm production in alpacas under Swedish conditions. Acta Vet Scand 58:10. doi: 10.1186/s13028-016-0191-x

2. Banda J, Evangelista S, Ruiz L, Sandoval R, Rodríguez C, Valdivia M, Santiani A. 2010. Efecto de dilutores en base a Tris, Tes y leche descremada en la criopreservación de espermatozoides obtenidos del epidídimo de alpaca. Rev Inv Vet Perú 21: 145-153. doi: 10.15381/rivep.v21i2.129

3. Brown DV, Senger PL. 1980. Influence of homologous blood serum on motility and head-to-head agglutination in nonmotile ejaculated bovine spermatozoa. Biol Reprod 23: 271-275. doi: 10.1095/biolreprod23.2.271

4. Cabrita E, Robles V, Cuñado S, Wallace JC, Sarasquete C, Herráez MP. 2005. Evaluation of gilthead sea bream, Sparus aurata, sperm quality after cryopreservation in $5 \mathrm{ml}$ macrotubes. Cryobiology 50: 273-284. doi: 10.1016/j.cryobiol.2005.02.005

5. Canorio $N$, Paredes $F$, Valdivia M. 2015. Agentes crioprotectores alternativos para el congelamiento lento de esperma-tozoides epididimarios de alpaca (Vicugna pacos). Rev Inv Vet Perú 26: 434-443. doi: 10.15381/rivep.v26i3.11185

6. Cheuquemán C, Merino O, Giojalas L, Von Baer A, Sánchez R, Risopatrón J. 2013. Assessment of sperm function parameters and DNA fragmentation in ejaculated alpaca sperm (Lama pacos) by flow cytometry. Reprod Domest Anim 48: 447-453.
7. Didion BA, Dobrinsky JR, Giles JR, Graves $C N$. 1989. Staining procedure to detect viability and the true acrosome reaction in spermatozoa of various species. Gamete Res 22: 51-57. doi: 10.1002/mrd.1120220106

8. Henkel R, MAAß G, Bödeker RH, Scheibelhut C, Stalf T, Mehnert C, Schuppe HC, et al. 2005. Sperm function and assisted reproduction technology. Reprod Med Biol 4: 7-30. doi: 10.1111/j.1447-0578.2005.00087.x

9. Klimowicz-Bodys MD, Batkowski F, Ochrem AS, Saviè MA. 2012. Comparison of assessment of pigeon sperm viability by contrast-phase microscope (eosin-nigrosin staining) and flow cytometry (SYBR-14/propidium iodide (PI) staining) [evaluation of pigeon sperm viability]. Theriogenology 77: 628-635. doi: 10.1016/j.theriogenology.2011.09.001

10. Malo C, Elwing B, Soederstroem L, Lundeheim N, Morrell JM, Skidmore $\boldsymbol{J} \boldsymbol{A}$. 2018. Effect of different freezing rates and thawing temperatures on cryosurvival of dromedary camel spermatozoa. Theriogenology 125: 4348. doi: 10.1016/j.therioge-nology.2018.07.037

11. Paniagua-Chávez CG, Jenkins J, Segovia M, Tiersch TR. 2006. Assessment of gamete quality for the eastern oyster (Crassostrea virginica) by use fluorescent dyes. Cryobiology 53: 128-138. doi: 10.1016/j.cryobiol.2006.05.001

12. Santiani A, Huanca W, Sapana R, Huanca T, Sepúlveda N, Sánchez $R$. 2005. Effects on the quality of frozenthawed alpaca (Lama pacos) semen using two different cryoprotectants and extenders. Asian J Androl 7: 303-309. doi: 10.1111/j.1745-7262.2005.00021.x 
13. Santiani A, Evangelista S, Valdivia M, Risopatrón J, Sánchez R. 2013. Effect of the addition of two superoxide dismutase analogues (Tempo and Tempol) to alpaca semen extender for cryopreservation. Theriogenology 79 : 842-846. doi: 10.1016/j.theriogenology.2012.12.012
14. Vetter CM, Miller JE, Crawford LM, Armstrong MJ, Clair JH, Conner MW, Wise LD, et al. 1998. Comparison of motility and membrane integrity to assess rat sperm viability. Reprod Toxicol 12: 105-114. doi: 10.1016/S0890-6238(97)00155-X 